\title{
ACREDITAÇÃO DO LABORATÓRIO DE METROLOGIA DIMENSIONAL DA UNIVERSIDADE DE BRASÍLIA, REGIÃO CENTRO-OESTE DO BRASIL
}

\section{ACCREDITATION OF DIMENSIONAL METROLOGY LABORATORY FROM UNIVERSITY OF BRASILIA, BRAZIL CENTER-WEST REGION}

\author{
Antonio Piratelli Filho* pirateli@unb.br \\ * Universidade de Brasilia
}

\begin{abstract}
Resumo: Este trabalho apresenta um estudo de caso envolvendo a acreditação de um Laboratório de Calibração da área de metrologia dimensional, pertencente à Universidade de Brasília, junto ao Instituto Nacional de Metrologia, Normalização e Qualidade Industrial (INMETRO). O laboratório localizado nesta Universidade Federal da região Centro-oeste brasileira, realiza calibração de instrumentos de medição de comprimento. A motivação para a acreditação tem origem na necessidade de reduzir as diferenças de desenvolvimento entre as regiões do Brasil, sendo que laboratórios inseridos nas Universidades tem um papel estratégico na sociedade, com um grande potencial para disseminar aspectos técnicos e organizacionais da qualidade. O desenvolvimento foi feito pela apresentação das exigências dos organismos de acreditação descritas pela Norma ABNT NBR ISO/IEC 17025:2005, sendo que as características intrínsecas e as ações implementadas no laboratório para atendimento a estes quesitos são descritos. A análise da demanda de serviços no laboratório nos últimos dez anos indicou uma tendência de crescimento, justificando a opção pela melhoria da qualidade dos serviços de calibração através da acreditação.
\end{abstract}

Palavras-chave: Qualidade. Acreditação de laboratório. Calibração.

Abstract: This work presents a case study of the accreditation of a calibration laboratory in dimensional metrology field by Instituto Nacional de Metrologia, Normalização e Qualidade Industrial (INMETRO). The accredited Laboratory was the Metrology Laboratory from Universidade de Brasília, a Government University located at Brazil Center-west Region. This Laboratory is used to carry out the calibration of length measuring instruments as Micrometers and Calipers. The motivation is associated to the efforts to reduce the differences in regional development in Brazil since University calibration laboratories play an important role in society to disseminate technical and organizational aspects of quality. The development begun by presenting the criteria established by ABNT NBR ISO/IEC 17025:2005 Standard and the efforts implemented to adjust the laboratory operational structure to the Standard requirements are described. The analysis of the demand for services at the laboratory during the past ten years showed a growing demand that justify the actions implemented to improve the quality of the services.

Key-words: Quality. Accreditation. Calibration

\section{INTRODUÇÃO}

A necessidade de crescimento econômico, apontada pelas políticas governamentais no Brasil e no mundo, tem catalisado esforços no sentido de ampliar as exportações como forma de proporcionar a geração de empregos e de renda. 
Uma estratégia adotada pelas empresas para atingir esta meta consiste na diversificação da oferta de produtos e de serviços e no investimento na qualidade. Do ponto de vista do mercado consumidor, a diversificação da oferta de um mesmo produto ou serviço torna a qualidade o fator decisivo na hora da escolha.

Costa e Farias Filho (2006), afirmaram que "uma condição para que os produtos e serviços de uma economia possam ter a liberdade de circular internacionalmente, sem a necessidade de re-ensaios ou inspeções, é a necessidade que eles possuam sua avaliação da conformidade declarada". Isto pode ser obtido através da implantação de sistemas de gestão da qualidade baseados em normas técnicas que definem a estrutura e documentos do sistema produtivo, como as normas da série ISO 9000 (Carvalho e Paladini, 2005).

As normas da série ISO 9000 visam melhorar a qualidade e a confiabilidade dos serviços e bens produzidos, através da implantação de um sistema da qualidade que proporciona uma padronização das necessidades e exigências dos clientes e fornecedores. Existe uma preocupação crescente das empresas em implantar as normas da série ISO 9000, sendo que a certificação está deixando de ser um diferencial e se tornando uma exigência do mercado nacional e principalmente internacional (Carvalho e Paladini, 2005).

Os laboratórios de ensaio e calibração, presentes nas próprias empresas ou como empresas que prestam serviços à indústria e comércio, a exigência do mercado motivou o desenvolvimento e implantação de normas específicas para atestar a qualidade dos serviços, envolvendo a comprovação da competência técnica e de gestão. A Norma adotada atualmente por estes laboratórios é a ABNT NBR ISO/IEC 17025:2005, a qual tem como referência a Norma ABNT NBR ISO 9001:2000, o que significa que os laboratórios que atenderem a primeira estarão operando também de acordo com a segunda (Olivares, 2006).

A certificação dos laboratórios segundo a Norma ABNT NBR ISO/IEC 17025 é feita através da acreditação junto ao Instituto Nacional de Metrologia, Normalização e Qualidade Industrial (INMETRO). A acreditação consiste no reconhecimento formal de que o laboratório solicitante tem competência técnica e administrativa para realizar as atividades a que se propõe, operando corretamente de acordo com os termos da Norma e assim prestando serviços de qualidade (INMETRO, 2009). 
Cassano (2003), afirmou que "utilizar ou ter um laboratório credenciado pelo INMETRO faz um bem não só a seus usuários, que terão um serviço mais eficiente e com garantia de precisão, nem apenas aos proprietários dessas organizações, que poderão prestar serviços a empresas exportadoras e internacionais". A expansão do mercado consumidor requer a demonstração da qualidade dos produtos, o que tem sido realizado pelo credenciamento dos laboratórios de ensaio e calibração aos organismos nacionais.

Nos últimos anos, alguns trabalhos relacionados à acreditação de laboratórios e instituições foram desenvolvidos. Antunes e Ribeiro (2005) apresentaram um estudo de caso da acreditação hospitalar, comparando os requisitos do Manual das Organizações Prestadoras de Serviços Hospitalares com os requisitos da Norma NBR ISO 19000:2000. Figueiredo e Pires (2007) apresentaram um estudo sobre a acreditação de um laboratório de análises clínicas, de acordo com o Programa de Acreditação de Laboratórios Clínicos (PALC). Moura e Costa (2008) apresentaram um estudo de caso envolvendo o uso de materiais de referência na acreditação de laboratórios de análises de águas. Noronha e Magalhães (2008) realizaram um estudo sobre implantação do sistema da qualidade em um laboratório de metrologia dimensional, verificando a conformidade da estrutura laboratorial em relação aos itens da Norma ABNT ISO/IEC 17025.

Em um país de dimensões como o Brasil, existe uma grande diferença quanto ao grau de desenvolvimento em função da localização regional. Analizando o panorama da distribuição dos laboratórios de calibração e ensaios acreditados pelo INMETRO, pode-se observar que sua distribuição geográfica é proporcional ao grau de desenvolvimento, sendo que a região Sudeste apresenta um número maior de laboratórios acreditados. Esta distribuição, referente aos laboratórios de calibração na área dimensional (medição de comprimento) acreditados até 19 de abril de 2009 , pode ser observada na figura 1 . Foi observado que $84 \%$ do laboratórios de metrologia dimensional do Brasil estavam localizados na região Sudeste. 


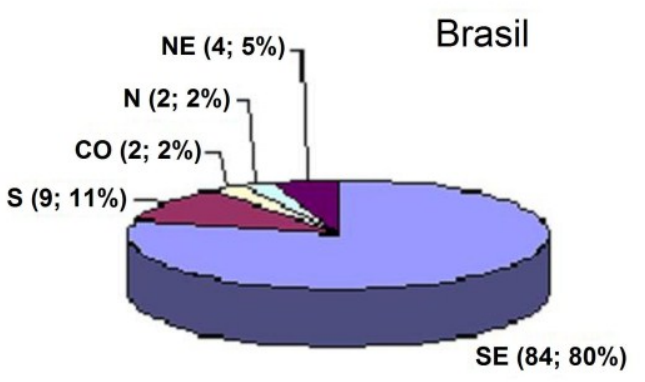

(a)

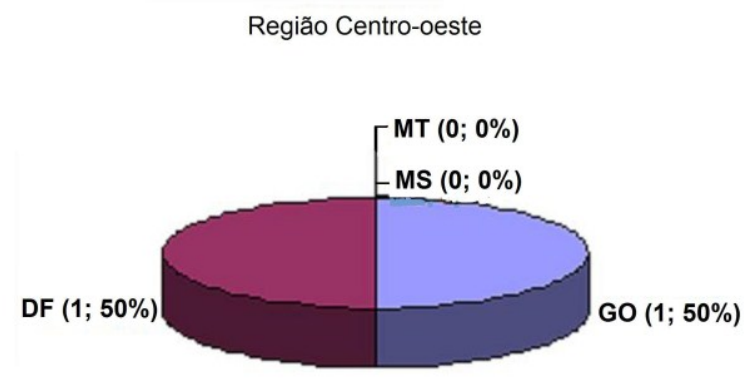

(b)

Figura 1 - Distribuição geográfica dos laboratórios de calibração (Dimensional) acreditados pelo INMETRO, no Brasil (a) e na região Centro-oeste (b).

Fonte: INMETRO (2009).

Em outras localidades, casos das regiões Norte, Nordeste e Centro-oeste do Brasil, a presença de laboratórios acreditados deve proporcionar condições básicas para o crescimento econômico, tais as facilidades promovidas pela proximidade do laboratório em relação ao mercado destes serviços. Atualmente, o crescimento econômico destas regiões, aliado à necessidade de implementação de normas de gestão da qualidade, tem motivado laboratórios pertencentes à Universidades que executam serviços de calibração a buscarem a acreditação segundo normas de gestão como a ABNT NBR ISO/IEC 17025.

Duarte et al. (2007) apresentaram um trabalho sobre a filiação do Laboratório de Medidas Elétricas da Universidade Regional do Noroeste do Estado do Rio Grande do Sul (UNIJUI) junto à Rede Metrológica Estadual. Neste trabalho, os autores argumentam que a implantação do sistema da qualidade foi consequência da exigência do mercado regional, que consistia basicamente de empresas do ramo metal-mecânico produtoras de máquinas e implementos agrícolas. A implantação foi feita pela adoção de um Manual da Qualidade, desenvolvido em concordância com o Vocabulário Internacional de Termos Gerais e Fundamentais em Metrologia (VIM) e com a Norma ABNT NBR ISO/IEC 17025:2001 (Duarte et al., 2007).

Os laboratórios das Universidades têm um papel estratégico muito importante, não apenas na prestação de serviços de calibração e ensaios à comunidade, mas também na disseminação e no desenvolvimento de conhecimento. Uma vez que estes laboratórios são em geral veículo usado na formação e treinamento de 
profissionais, uma grande quantidade de pessoas têm contato com as tecnologias e técnicas aplicadas. Além disto, há ainda o desenvolvimento de conhecimento que é realizado a partir das técnicas aplicadas, envolvendo alunos de graduação e pósgraduação.

$\mathrm{Na}$ região sudeste, pode-se destacar alguns laboratórios de calibração acreditados pelo INMETRO e que foram nucleados ou estão ligados à Universidades, caso do Laboratório de Metrologia Mecânica do Instituto de Pesquisas Tecnológicas (IPT, SP), do Laboratório de Metrologia da Universidade Estadual de Campinas (UNICAMP, SP) e do Laboratório de Metrologia do Instituto Tecnológico da Pontifície Universidade Católica (ITUC, RJ), dentre outros. Na região Sul, pode-se mencionar o Laboratório CMI - Fundação CERTI, acreditado pelo INMETRO. Estes laboratório tem um papel importante na região onde estão inseridos e tem destaque no cenário nacional tanto pelos serviços de calibração como pela formação de pessoal qualificado através de cursos.

Com o intuito de sistematizar as informações e estimular a acreditação de laboratórios ligados à Universidades e Centros de pesquisa, especialmente em regiões economicamente menos desenvolvidas, este trabalho apresenta um estudo de caso envolvendo a acreditação pelo INMETRO de um laboratório de calibração de uma Universidade da região Centro-oeste do Brasil. O Laboratório em questão é o Laboratório de Metrologia (LM) da Universidade de Brasília (UnB), atuando na área dimensional, que presta serviços de calibração desde 1998. As exigências dos organismos de acreditação descritas pela Norma ABNT NBR ISO/IEC 17025:2005 são apresentadas e os meios implementados no laboratório para atendimento aos quesitos são descritos e discutidos.

\section{ACREDITAÇÃO DE LABORATÓRIOS}

A acreditação consiste no reconhecimento formal pelos organismos de certificação de que um laboratório de calibração ou de ensaio tem competência para executar suas atividades. No caso de laboratórios de calibração, estes organismos se baseiam na Norma ABNT NBR ISO/IEC 17011:2005, a qual define acreditação como "atestação de terceira-parte relacionada a um organismo de avaliação da 
conformidade (OAC), comunicando a demonstração formal da sua competência para realizar tarefas específicas de avaliação da conformidade".

Apesar do caráter voluntário, tem sido observada uma tendência crescente relacionada à busca da acreditação de laboratórios prestadores de serviços. Qualquer laboratório prestador de serviços de calibração ou de ensaios pode solicitar a acreditação, como política da sua direção ou como exigência do mercado consumidor dos seus serviços, qualquer que seja seu porte ou sua área de atuação. Pode ser concedida a laboratórios permanentes, temporários ou móveis, para realizar os serviços de calibração dentro e fora das suas instalações.

No Brasil, o organismo responsável pela acreditação de laboratórios de calibração e ensaios é o INMETRO. A concessão da acreditação para um laboratório de calibração é feita de acordo com a área da metrologia atendida, podendo ser dimensional, pressão, força, massa, elétrica, dentre outras. No caso de laboratórios de ensaios, a concessão é feita por modalidade de ensaio, para atender a uma determinada norma ou certificar um método de ensaio desenvolvido pelo próprio laboratório (INMETRO, 2009).

As organizações acreditadas apresentam vantagens sobre as não acreditadas, dentre as quais podem ser mencionadas:

- evidência da competência do laboratório, verificada e comprovada por uma equipe de avaliadores independentes, especializados nas áreas de atuação do laboratório;

- conquista de novos mercados, motivada pela garantia da competência técnica;

- confiança dos clientes nos serviços solicitados, dispensando a execução de auditorias próprias nos laboratórios;

- melhoria das práticas e dos procedimentos adotados, através de autoavaliação e de auditorias realizadas pelo organismo de acreditação;

- reconhecimento internacional devido aos acordos de reconhecimento mútuo assinados pelo INMETRO;

- maior abrangência da divulgação dos serviços prestados, os quais são oferecidos pelo INMETRO através do seu catálogo oficial.

Ainda, os usuários do laboratório acreditado podem efetuar tomadas de decisão com menor risco de erro, o que reduz a probabilidade de ter seus produtos 
rejeitados pelo comprador devido a uma não conformidade. As oportunidades comerciais dos usuários são extendidas devido à aceitação internacional dos serviços prestados por um laboratório acreditado.

\section{ETAPAS DO PROCESSO DE ACREDITAÇÃO}

O laboratório que está solicitando ou que deseja solicitar a acreditação deve observar alguns requisitos básicos antes de iniciar o processo. Primeiramente, é necessário verificar qual das modalidades de acreditação oferecidas se adequa às necessidades do laboratório. Cada modalidade depende da atividade realizada, tendo como base normas diferentes, a Norma NBR ISO/IEC 17025 ou a Norma BPL - Boas Práticas de Laboratório. No caso de laboratórios de calibração, a norma NBR ISO/IEC 17025 deve ser implementada (Olivares, 2006).

O primeiro passo do processo de acreditação consiste da solicitação formal da acreditação, seguida de uma análise crítica da solicitação e indicação da equipe de avaliação, visita de pré-avaliação, análise da documentação, comparações interlaboratoriais, avaliação inicial, decisão sobre a acreditação e manutenção da acreditação. A figura 2 apresenta um fluxograma com estas etapas, as quais estão apresentadas na sequência (INMETRO, 2009). 


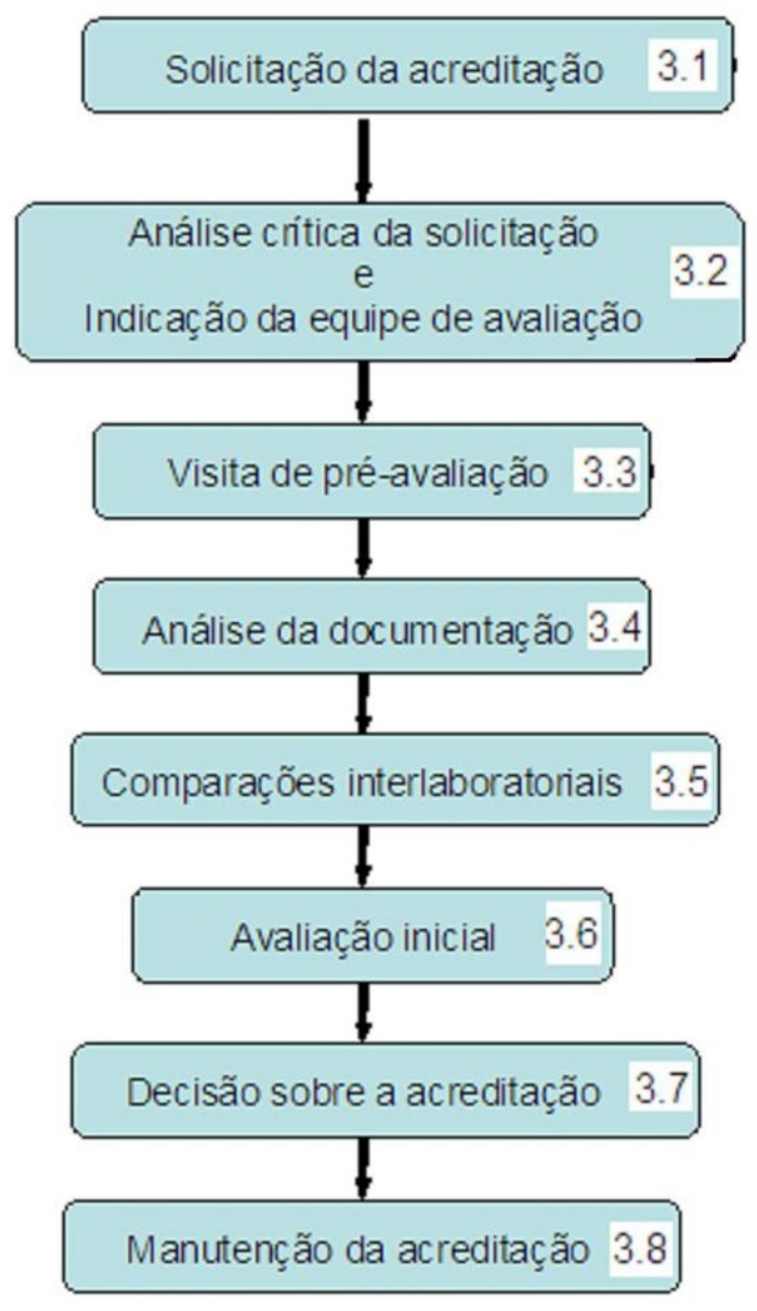

Figura 2 - Fluxograma do processo de acreditação. Fonte: INMETRO (2009)

\subsection{Solicitação da Acreditação}

Para que um laboratório de ensaio ou calibração solicite a acreditação, deve primeiramente verificar junto ao INMETRO todos os documentos, as regras e as orientações para a acreditação, assim como os formulários que devem ser preenchidos. O primeiro formulário a ser preenchido para formalizar a solicitação da acreditação é o FOR CGCRE-001: Solicitação de Acreditação de Laboratório, o qual deve ser encaminhado à Divisão de Credenciamento de Laboratórios (DICLA), pertencente ao INMETRO. Esse formulário deve ser complementado por um anexo que depende do escopo da proposta (INMETRO, 2009). 
Entretanto, antes de formalizar a solicitação, o laboratório deve certificar que seu sistema de gestão está atende às exigências dos requisitos da acreditação do seu caso em particular. Esta verificação deve ser feita através da realização de uma auditoria interna e de uma reunião para análise crítica do sistema de gestão. Os preparativos para estas avaliações equivalem à verificação do atendimento das questões técnicas particulares a área de acreditação e das questões administrativas.

No caso de laboratórios de metrologia da área dimensional, como o LM da Universidade de Brasília, as questões técnicas importantes dizem respeito ao controle da temperatura e da umidade nas instalações onde as calibrações e medições são realizadas. Uma temperatura de $20^{\circ} \mathrm{C}$ deve ser mantida, com variação admitida de $\pm 1{ }^{\circ} \mathrm{C}$. A umidade relativa do ar deve permancer entre 40 e $60 \%$. Estas variáveis ambientais devem ser continuamente monitoradas e registradas, especialmente durante a realização das medições. Cuidados com partículas de poeira, vibrações e iluminação devem ser tomados para garantir que não influenciam nos resultados. Todos os padrões usados nas calibrações e medições devem ser calibrados por laboratórios pertencentes à Rede Brasileira de Calibração (RBC), de forma a garantir a rastreabilidade dos resultados. O técnico executor das atividades deve ser preparado através da realização de cursos de treinamento na área.

As questões administrativas que devem ser previamente verificadas dizem respeito aos aspectos gerenciais e financeiros. Devido ao laboratório estar vinculado ao Departamento de Engenharia Mecânica (ENM), Faculdade de Tecnologia (FT) da UnB, as decisões e políticas implementadas devem ser aprovadas pelo Gerente Geral ou Coordenador do laboratório em conjunto com o Chefe do ENM. A prestação de serviços de calibração deve ser caracterizado como um projeto de extensão da Universidade, devidamente formalizado junto à unidade a que está vinculado. Como estas atividades resultam num retorno financeiro, deve existir um algum órgão para gerenciar os recursos do projeto. No caso do LM, este gerenciamento é feito pela Fundação de Empreendimentos Científicos e Tecnológicos (FINATEC), ligada à UnB. Toda movimentação financeira passa necessariamente por essa Fundação, tanto no recebimento de recursos como na execução de gastos ou investimentos.

No caso dos laboratórios cuja modalidade de acreditação é baseada nas normas NBR ISO/IEC 17025, o sistema de gestão e as políticas devem estar definidas em um Manual da Qualidade. Se o laboratório pertencer a uma empresa 
ou organização que tenha um Manual da Qualidade, é necessário verificar deve-se verificar se os procedimentos, as políticas e as responsabilidades especificadas para o laboratório estão bem definidas, em concordância com os requisitos da acreditação.

\subsection{Análise Crítica da Solicitação e Indicação da Equipe de Avaliação}

O pedido de acreditação é verificado pela DICLA/INMETRO, quanto a documentação encaminhada e necessidade de complementação. O processo é aberto e a Coordenação Geral de Credenciamento (CGCRE) da DICLA faz uma análise crítica para avaliar se todos os recursos necessários para o processo de avaliação estão disponíveis. Caso a avaliação seja positiva, um técnico de acreditação é designado como responsável pelo gerenciamento do processo e para realizar o contato com o laboratório. Uma equipe de avaliadores é definida em função do escopo de acreditação solicitado e da disponibilidade do avaliador. A equipe é informada ao laboratório, que pode se manifestar alteração caso tenha uma justificativa.

\subsection{Visita de Pré-Avaliação}

A visita de pré-avaliação pode ser realizada a pedido do laboratório ou caso a equipe de avaliação do INMETRO julgue necessário, a partir da análise da documentação. O objetivo desta pré-avaliação é a verificar a preparação do laboratório para a avaliação e proporcionar um conhecimento prévio do laboratório e da sua equipe pelos avaliadores. Nesta visita, pode haver a detecção de possíveis não-conformidades, a discussão da adequação do escopo solicitado e o esclarecimento de dúvidas quanto ao processo.

\subsection{Análise da Documentação}

A análise da documentação pode ser dividida em duas partes, sendo a primeira referente à análise dos requisitos da gerência e a segunda referente aos requisitos técnicos. 
A análise dos requisitos da gerência é baseado na avaliação do Manual da Qualidade (MQ) do laboratório. Essa análise tem como objetivo verificar se $\mathrm{OMQ}$ contém ou faz referência a todos os itens da norma de acreditação, se contém as políticas e os procedimentos complementares estabelecidos nos requisitos da acreditação, a verificação do nível de implementação do sistema de gestão e da qualidade das análises críticas e das auditorias internas.

A análise dos requisitos técnicos visa verificar a adequação dos equipamentos, dos registros de cálculos, dos padrões de referência, dos cálculos de incerteza, dos procedimentos e demais documentos relacionados à execução dos serviços.

A detecção de não conformidades durante a análise dos documentos exige a implementação de ações corretivas pelo laboratório, sendo que as evidências destas ações devem ser encaminhadas ao técnico de acreditação.

\subsection{Comparações Interlaboratoriais}

As comparações interlaboratoriais são aplicadas pela CGCRE para verificar a competência do laboratório na realização das calibrações ou dos ensaios. Nestas comparações, o laboratório solicitante da acreditação deve calibrar ou ensaiar um item pertencente ao INMETRO para avaliar a melhor incerteza de acordo com os procedimentos propostos. Caso ocorra um resultado insatisfatório, o laboratório deve fazer uma investigação para identificar e eliminar as causas do problema e deve confirmar a eficácia das ações tomadas por meio de uma nova comparação. As ações corretivas implementadas devem ser encaminhadas ao INMETRO, sendo que um novo resultado insatisfatório proporciona a retirada dos serviços correspondentes do escopo da acreditação ou até o arquivamento do processo caso haja um comprometimento total dos serviços solicitados.

\subsection{Avaliação Inicial}

A avaliação inicial consiste em uma visita da equipe de avaliação às instalações do laboratório com o objetivo de verificar a implementação do sistema de gestão e a competência técnica do laboratório. A equipe de avaliação deve verificar 
os documentos e os registros do sistema de gestão e os registros dos serviços prestados pelo laboratório, os quais devem estar disponíveis. Durante a avaliação, os laboratórios devem estar preparados para realizar as calibrações ou os ensaios para os quais solicita a acreditação e ter pessoal da gerência e pessoal técnico disponíveis para que a equipe de avaliação possa evidenciar o atendimento aos requisitos da acreditação. Cada avaliador deve estar acompanhado de um representante do laboratório, que será avaliado quanto ao seu conhecimento.

O resultado da avaliação é apresentada ao final, através de uma reunião da equipe de avaliadores com a direção do laboratório. Nesta reunião, são discutidas as possíveis ações corretivas, o prazo para tratar essas ações corretivas e a recomendação à DICLA quanto à acreditação ou não do laboratório. As ações corretiva implementadas deve ser enviadas aos técnicos de acreditação dentro do prazo estabelecido, os quais devem fazer uma verificação da pertinência ou não das evidências apontadas. No caso de implementação de ações corretivas, o laboratório será acreditado após os avaliadores evidenciarem tal implementação. Caso o laboratório demonstre ter capacidade de implementar ações corretivas relativas a apenas uma parte do escopo da acreditação solicitado, pode optar pela retirada dos ensaios ou calibrações que não tem capacidade de atender.

\subsection{Decisão Sobre a Acreditação}

O coordenador da CGCRE é o responsável por decidir quanto à concessão ou não da acreditação para o laboratório, sendo que essa decisão é baseada nas recomendações da equipe avaliadora, do chefe de equipe, do chefe da DICLA e no parecer da comissão de acreditação. A formalização da acreditação é feita através de um contrato assinado pelo responsável pelo laboratório ou organização e o INMETRO. O certificado de acreditação é emitido e enviado ao laboratório após a assinatura do contrato por ambas as partes, inserindo assim o nome no catálogo de laboratórios credenciados. O laboratório passa a fazer parte da Rede Brasileira de Calibração (RBC) ou Rede Brasileira de Laboratórios de Ensaios (RBLE), devendo usar o selo com o logotipo da RBC ou RBLE nos certificados de calibração ou ensaio emitidos. 


\subsection{Manutenção da Acreditação}

A verificação periódica do atendimento aos requisitos e regulamentos da acreditação é feita através de reavaliações a cada dois anos, contados a partir da reavaliação anterior, sendo que a primeira deve ser realizada no máximo após um ano da acreditação inicial. Essas verificações são realizadas através de um procedimento similar ao da avaliação inicial, contendo inclusive as auditorias de medição ou ensaios de proficiência. O INMETRO realiza ainda o monitoramento da acreditação através da análise dos documentos do laboratório (INMETRO, 2009).

\section{IMPLANTAÇÃO DO SISTEMA DA QUALIDADE NO LABORATÓRIO DE METROLOGIA}

O Laboratório de Metrologia da Universidade de Brasília (UnB), localizado no Distrito Federal, região Centro-oeste do Brasil, tem sido empregado para aulas de cursos de graduação e pós-graduação da Universidade. Além destas atividades, presta serviços de calibração de instrumentos de medição de comprimento (dimensional) desde 1998, tendo solicitado acreditação junto ao INMETRO em agosto de 2007, contemplada em 10/03/2009, fazendo parte da Rede Brasileira de Calibração (RBC).

Com a evolução das atividades de calibração, a gerência do laboratório decidiu implantar um sistema da qualidade inicialmente com a finalidade de melhoria da qualidade dos serviços prestados. O sistema da qualidade foi implantado em concordância com os requisitos da Norma NBR ISO/IEC 17025:2005, tendo sido elaborados os documentos relacionados à parte técnica e à parte administrativa do laboratório. A estrutura e hierarquia dos documentos elaborados estão apresentados na Figura 3. Nesta figura, pode ser observado que o Manual da Qualidade (MQ) se encontra no primeiro nível, o mais elevado na hierarquia, seguido pelos procedimentos técnicos $(\mathrm{PT})$, administrativos $(\mathrm{PA})$ e de cálculo da incerteza de medição $(\mathrm{PCl})$ e os manuais de operação $(\mathrm{MO})$, no segundo nível, sendo que os documentos da qualidade (DQs) estão no terceiro nível. 


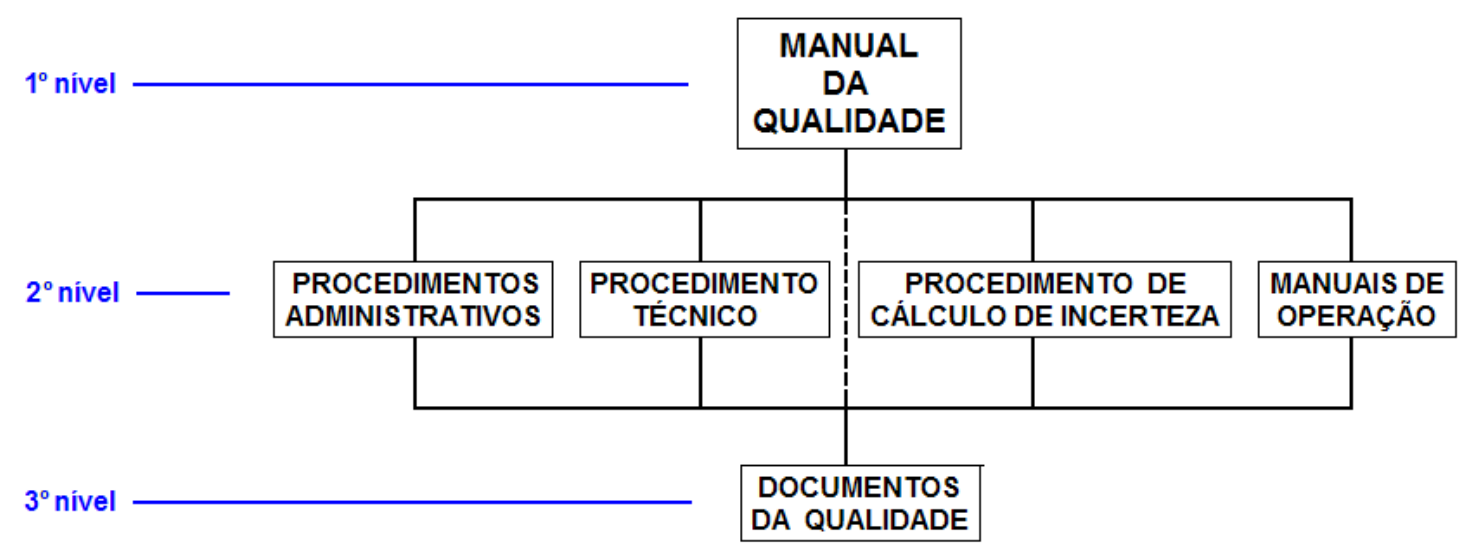

Figura 3 - Hierarquia da documentação.

Após a conclusão desta fase de elaboração de documentos, uma revisão minuciosa de toda a documentação existente foi feita, tanto a nível gerencial quanto a nível técnico. Como o escopo de calibração almejado foi associado à calibração de Micrômetros, foi feita uma revisão somente da documentação técnica relativa a esse instrumento.

Uma auditoria interna foi realizada para detectar as não conformidades em relação à Norma NBR ISO/IEC 17025, com a presença de um auditor externo colaborando com o pessoal do laboratório. A metodologia empregada na análise dos documentos consistiu na observação de cada item da Norma NBR ISO/IEC 17025, verificando se estes atendiam às exigências. Em caso positivo, foi feita revisão nos documentos para verificar se realmente atendiam à Norma. Em caso negativo, foram criados documentos para corrigir a não conformidade. Este processo proporcionou uma melhoria do sistema da qualidade, uma vez que alterações, cancelamento e o desenvolvimento documentos foram realizados.

Uma comparação interlaboratorial preliminar foi feita para validação do procedimento de calibração adotado, especificado no Procedimento Técnico (PT) do laboratório, e para a determinação da melhor incerteza de medição na calibração de micrômetros, conforme especificado no Procedimento de Cálculo da incerteza de medição (PCl). Esta comparação foi feita enviando um Micrômetro para calibração em um outro laboratório acreditado pelo INMETRO e pertencente à Rede Brasileira de Calibração (RBC). O mesmo Micrômetro foi calibrado no Laboratório de Metrologia da UnB e os certificados de calibração emitidos pelos dois laboratórios 
foram comparados com base no cálculo do erro normalizado, admitindo o laboratório da RBC como referência (INMETRO, 2009).

Após estas etapas de preparação, o processo de acreditação foi iniciado pelo encaminhamento dos documentos do sistema da qualidade ao INMETRO. As etapas apresentadas na figura 2 e descritas no item 3 foram seguidas, sendo que a visita de pré-avaliação não necessária.

O Gerente Geral do LM foi o responsável pelo encaminhamento da solicitação formal de acreditação (item 3.1). Através de correspondência registrada, contendo os documentos do SQ do LM, o pedido foi protocolado no INMETRO. Para os novos pedidos, está sendo viabilizada a solicitação através de sistema disponível na internet, o qual substitui o envio de documentos impressos (INMETRO, 2009).

Após cerca de três meses do envio dos documentos, o INMETRO designou uma equipe de avaliação para o processo, evidenciando a procedência do pedido (item 3.2). A equipe de avaliação não solicitou uma visita de pré-avaliação do LM (item 3.3). Neste período, foi feita a análise da documentação (item 3.4) e os documentos enviados foram aprovados na íntegra.

Uma nova comparação interlaboratorial (item 3.5) foi executada antes da visita de avaliação inicial. Nesta comparação, um micrômetro digital pertencente ao INMETRO foi calibrado pelo LM e os resultados foram devolvidos junto com o instrumento para análise dos resultados (cálculo do erro normalizado) e emissão do relatório pelo INMETRO. Este processo foi usado para definição da melhor capacidade de medição do laboratório, caracterizada pela incerteza de medição do instrumento.

A visita de avaliação inicial (item 3.6) contou com a presença de dois consultores do INMETRO, um para verificar os aspectos da área administrativa e outro os aspectos da área técnica pertinentes à norma NBR ISO/IEC 17025. O Gerente Geral do LM foi auditado, juntamente com o técnico executor das calibrações e os estagiários. A análise dos documentos e do funcionamento do LM resultou em um relatório de avaliação que apontou não conformidades no sistema da qualidade do laboratório. Dentre estas não conformidades, questões pertinentes a alterações no procedimento de cálculo da incerteza de medição e alterações em documentos adminstrativos foram reportadas. A equipe de avaliação realizou uma reunião de fechamento com o pessoal do LM, na presença do Chefe do 
Departamento de Engenharia Mecânica da UnB, onde foi comunicado que seria recomendada a acreditação do laboratório após o tratamento e a correção das não conformidades, desde que realizado num prazo de três meses.

A decisão final sobre a acreditação (item 3.7) foi tomada após a avaliação das correções das não conformidades apontadas no relatório da avaliação, sendo positiva. Assim, o Laboratório de Metrologia da UnB foi acreditado pelo INMETRO, passando a fazer parte da Rede Brasileira de Calibração (RBC), sob o número CAL 429. O tempo total decorrido desde o início do processo foi de aproximadamente um ano e meio.

A manutenção da acreditação (item 3.8) é sustentada somente após avaliações feitas a cada dois anos, entretanto esta depende de outros fatores. Ao contrário de empresas privadas, que dependem exlusivamente do lucro para sua sobrevivência, um laboratório de uma Universidade Federal depende da política do Departamento em que está inserido, da disponibilidade de pessoal fornecido pela administração da Universidade e ainda da disponibilidade de serviços na sua área de atuação, entre outros. A disponibilidade de serviços equivale à demanda, sendo que precisa apresentar um nível mínimo para que o laboratório possa arcar com os custos da manutenção da acreditação, como aqueles relacionados ao material usado e ao pagamento dos serviços prestados pelo órgão avaliador.

Uma análise da demanda de serviços junto ao Laboratório de Metrologia, registrada no decorrer dos últimos dez anos, foi feita para observar o fluxo das atividades de calibração desenvolvidas antes e logo após a acreditação.

A evolução da demanda de serviços de calibração, em função da quantidade e do tipo de instrumento calibrado, está apresentada na figura 4. Como pode ser observado, a calibração de Trenas foi o serviço mais solicitado, apresentando picos na demanda em 2003, 2006 e 2009. Outros instrumentos, como o Micrômetro, apresentaram demanda inferior, em quantidade, porém apresentaram a mesma tendência de crescimento ao longo do tempo. Um crescimento acentuado da procura de serviços foi registrado no ano de 2009, tanto para calibrações dentro do escopo do laboratório (Micrômetros) como fora do escopo (outros instrumentos), que foi associada ao credenciamento obtido. 


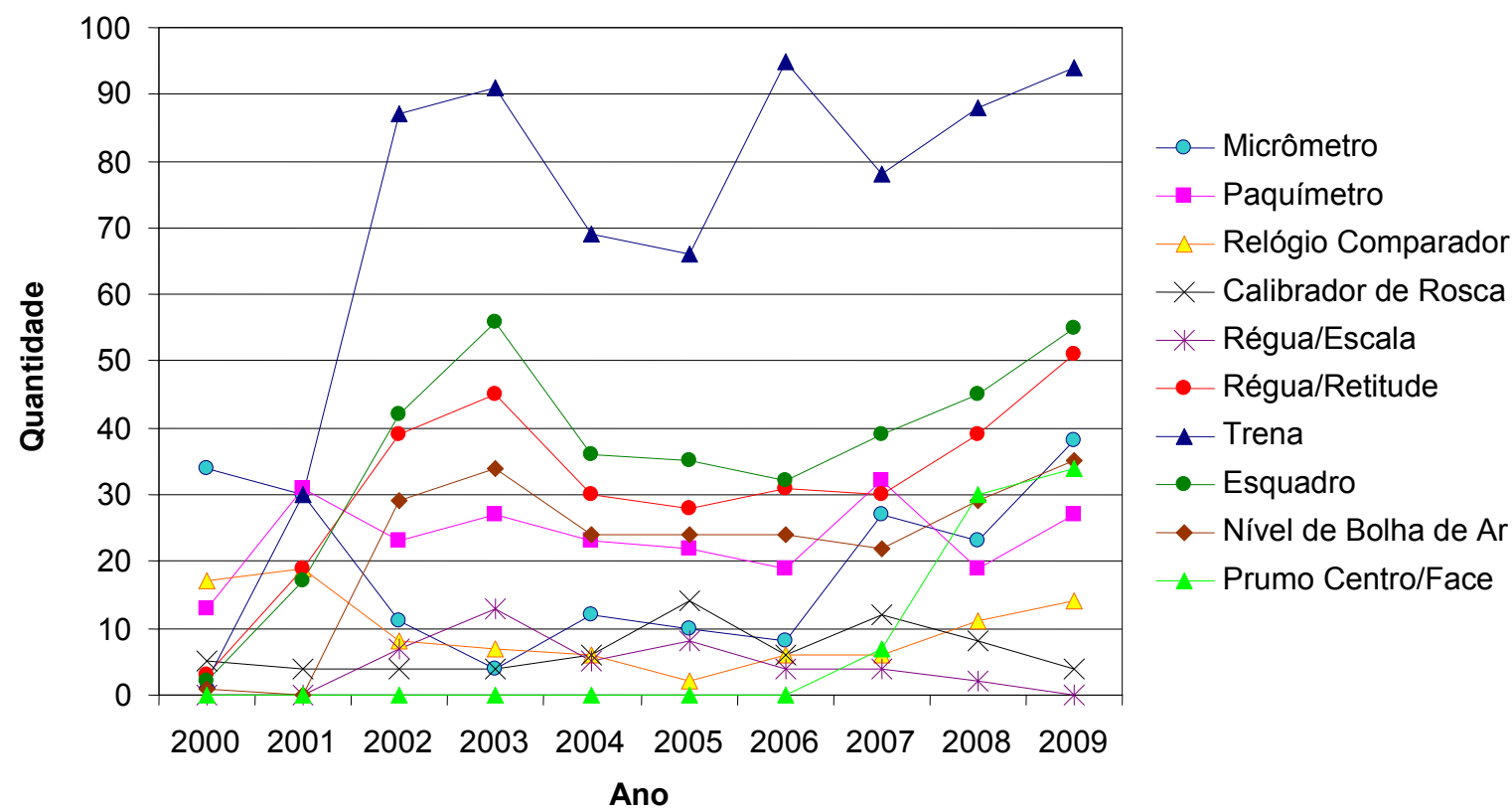

Figura 4 - Gráfico comparativo dos instrumentos calibrados pelo laboratório desde o ano 2000.

Uma análise dos dados da demanda em função do setor da economia no qual a empresa solicitante está inserida está apresentada na figura 5. Pode ser observado que a indústria da construção civil responde pela maior parte dos pedidos de calibração de instrumentos do Laboratório de Metrologia, apresentando crescimento gradativo ao longo do período relatado. Já a indústria mecânica e o setor de serviços (comércio), juntos, apresentaram uma demanda estável e constante no mesmo período. Para corroborar com estes resultados, foi observado que a região Centro-oeste do Brasil apresentou um crescimento populacional acentuado neste período, em especial nos grandes centros urbanos, sendo que as empresas do ramo da construção civil tem procurado certificação pelas normas da série ISO 9000 para enfrentar a crescente competitividade. 


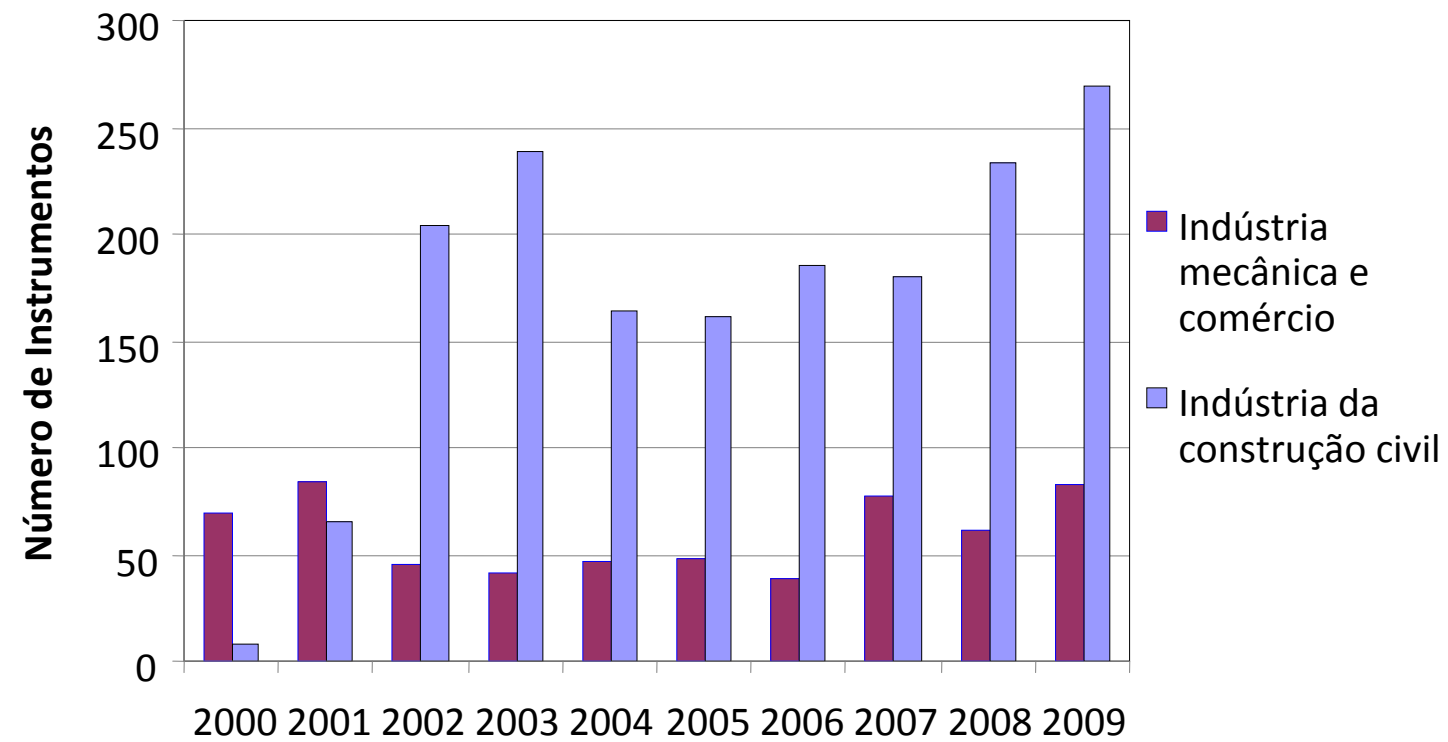

Ano

Figura 5 - Gráfico comparativo por setor da economia atendido pelo laboratório.

\section{CONCLUSÕES}

Um estudo de caso referente a acreditação do Laboratório de Metrologia da Universidade de Brasília possibilitou sistematizar e resumir a informação sobre o processo de acreditação de laboratórios pelo INMETRO, em particular de laboratórios de calibração. Neste processo, a sequência de etapas do processo de acreditação e a preparação e revisão da documentação da qualidade foram abordadas.

A preparação do laboratório foi de grande importância no processo de acreditação, sendo que os aspectos técnicos relacionados à área de atuação do laboratório (dimensional) envolveram o controle das condições ambientais, como temperatura e umidade relativa do ar, calibração dos padrões e treinamento operacional do corpo técnico. A implantação do sistema da qualidade, consistindo da elaboração e da revisão dos documentos da qualidade antes da formalização do pedido de acreditação junto ao INMETRO, contribuiu de forma decisiva para a aprovação do pedido. Uma das maiores dificuldades neste processo foi associada ao envolvimento da equipe na proposta e na adoção de hábitos como a formalização 
dos registros das atividades realizadas. As duas comparações interlaboratoriais realizadas, antes e durante o processo de acreditação, proporcionaram ajustes no procedimento de calibração e de cálculo da incerteza de medição, bem como da determinação da melhor incerteza do laboratório para o serviço de calibração solicitado.

Foi possível avaliar que numa entidade como uma Universidade Federal a manutenção de um laboratório acreditado pode ser feita uma vez que a demanda de serviços permite captar recursos para pagamento dos custos de manutenção e acreditação. Entretanto, a manutenção depende ainda de outros fatores, ligados à política da unidade onde está inserido e da disponibilidade de pessoal para executar as atividades. $O$ incremento da qualidade proporcionado pela acreditação pode estimular o desenvolvimento regional e permitir a disseminação do conhecimento através de cursos e da formação de alunos.

A distribuição de laboratórios de calibração no Brasil é ainda muito desigual nas diferentes regiões geográficas. Regiões economicamente menos desenvolvidas apresentam carência de laboratórios acreditados que poderiam proporcionar condições mais favoráveis para o crescimento econômico. Embora existam publicações sobre certificação da qualidade, muito pouco foi encontrado sobre o processo de acreditação de laboratórios, especialmente sobre laboratórios pertencentes à Universidades. Neste sentido, este trabalho pode orientar os laboratórios de outras Universidades Federais e Estaduais que estão em busca da acreditação dos seus laboratórios de ensino e pesquisa.

\section{AGRADECIMENTOS}

Os autores agradecem o apoio financeiro fornecido pela FINEP - Financiadora de Estudos e Projetos e pela FAPDF - Fundação de Apoio à Pesquisa do Distrito Federal para a realização deste trabalho.

\section{REFERÊNCIAS}

ANTUNES, F e RIBEIRO, J.L. Acreditação hospitalar: um estudo de caso. Revista Produção Online, v.5, n.1, 2005. 
ASSOCIAÇÃO BRASILEIRA DE NORMAS TÉCNICAS. Norma ABNT NBR ISO/IEC 17011: Avaliação de conformidade - Requisitos gerais para os organismos de acreditação que realizam acreditação de organismos de avaliação de conformidade. Rio de Janeiro: ABNT, 2005. 23 p.

Norma ABNT NBR ISO/IEC 17025: Requisitos gerais para a competência de laboratórios de ensaio e calibração. Rio de Janeiro: ABNT, 2005. 31 p.

CASSANO, D. Credenciamento: solução para quem usa ou oferece serviços de ensaio e calibração. Metrologia e Instrumentação, v. 2, 2003.

CARVALHO, M.M. e PALADINI, E.P. Gestão da qualidade: teoria e casos. Rio de Janeiro, Elsevier , 2005. 355 p.

COSTA, A.F.; FARIAS FILHO, J.R. A acreditação de organismos de avaliação da conformidade. Metrologia e Instrumentação, v. 5, n. 41, p. 12-19, 2006.

DUARTE, L.C.S., SACKSER, G., KOTLINSKI, E., SANTOS, A.R.J. ;ECKHARDT, M. A influência dos sistema de gestão da qualidade no Laboratório de Metrologia Elétrica da UNIJUÍ. In: ENCONTRO NACIONAL DE ENGENHARIA DE PRODUÇÃO, 27. Foz do Iguaçu, 2007. Anais... . Foz do Iguaçu, 2007.

FIGUEIREDO, A.C. e PIRES, M.B. Um sistema de gestão da qualidade: a acreditação de um laboratório de análises clínicas. In: In: ENCONTRO NACIONAL DE ENGENHARIA DE PRODUÇÃO, 27. Foz do Iguaçu, 2007. Anais... . Foz do Iguaçu, 2007.

INSTITUTO NACIONAL DE METROLOGIA, NORMALIZAÇÃO E QUALIDADE INDUSTRIAL. Disponível em: <http://www.inmetro.gov.br>. Acesso em: 19 abr. 2009.

MOURA, S.S.; COSTA, S.R.R. Estudo de caso em laboratórios de análises de águas: utilização de materiais de referência. In: ENCONTRO NACIONAL DE ENGENHARIA DE PRODUÇÃO, 28. Rio de Janeiro, 2008. Anais... Rio de Janeiro, 2008.

NORONHA, J.L. ;MAGALHÃES, J.G. Implantação do sistema de gestão da qualidade para Laboratório de Metrologia de acordo com a NBR ISO/IEC 17025:2005. In: ENCONTRO NACIONAL DE ENGENHARIA DE PRODUÇÃO, 28. Rio de Janeiro, 2008. Anais... Rio de Janeiro, 2008.

OLIVARES, I.R.B. Gestão da qualidade em laboratórios. Campinas: Átomo, 2006. $100 \mathrm{p}$.

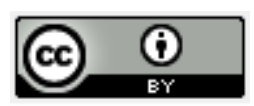

Artigo recebido em 13/11/2009 e aceito para publicação em 09/12/2010 